\title{
Activated TiC-SiC Composite for Natural Gas Upgrading via Catalytic Oxyhalogenation
}

\author{
Guido Zichittella, ${ }^{+[a]}$ Begoña Puértolas, ${ }^{+[a]}$ Sebastian Siol,${ }^{[b]}$ Vladimir Paunović, ${ }^{[a]}$ Sharon Mitchell, ${ }^{[a]}$ and \\ Javier Pérez-Ramírez ${ }^{\star[a]}$
}

\begin{abstract}
Alkane oxyhalogenation has emerged as an attractive catalytic route for selective natural gas functionalization to important commodity chemicals, such as methyl halides or olefins. However, few systems have been disclosed to be active and selective in these reactions. Here, we identify a novel and highly efficient TiC-SiC composite for methane and ethane oxyhalogenation. Detailed characterization elucidates the kinetics and mechanism of the selective activation under reaction conditions to yield $\mathrm{TiO}_{2}$-TiC-SiC. This catalyst outperformed bulk $\mathrm{TiO}_{2}$, one of the best reported catalysts, reaching up to $85 \%$ selectivity and up to 3 times higher titanium-specific space-time-yield of methyl halides or ethylene. This was attributed to fact that the active $\mathrm{TiO}_{2}$ phase generated in situ is embedded in the thermally conductive $\mathrm{SiC}$ matrix, facilitating heat dissipation thus improving selectivity control.
\end{abstract}

\section{Introduction}

The selective activation of the inert $\mathrm{C}-\mathrm{H}$ bonds in methane and ethane, the principal components of natural gas, is one of the key challenges in catalysis research. ${ }^{[1-3]}$ As abundant resources, these alkanes offer a huge potential for the manufacture of higher value chemicals and fuels. Nevertheless, over $30 \%$ of the world's natural gas is trapped in small basins and/or in remote areas, where its valorization via established technologies such as energy-intensive steam reforming or steam cracking is not economical. ${ }^{[4-7]}$ Consequently, less than $10 \%$ of the global annual gas production is currently used for the manufacture of commodities, while ca. $3.5 \%$, a share which is worth ca. 13 billion USD, is flared at oil and gas fields or refineries. ${ }^{[8,9]}$ Over the last decades, alternative alkane activation routes, including the oxidative coupling and partial oxidation of methane ${ }^{[10]}$ jointly with the partial oxidation ${ }^{[11,12]}$ and oxidative dehydrogenation ${ }^{[13,14]}$ of ethane to targeted products (e.g. carbon monoxide, methanol, or olefins), have been intensively studied. However, these paths typically suffer from limited selectivity, which stems from the fact that the intermediates and products are easier to activate than the alkane reactants.

Halogen-based processes find wide applications in the chemical

[a] G. Zichittella, ${ }^{+}$Dr. B. Puértolas, ${ }^{+}$V. Paunović, Dr. S. Mitchell, Prof. J. Pérez-Ramírez

Department of Chemistry and Applied Bioscience, ETH Zurich Institute for Chemical and Bioengineering

Vladimir-Prelog-Weg 1, 8093 Zurich (Switzerland)

E-mail: jpr@chem.ethz.ch

[b] Dr. S. Siol

EMPA, Swiss Federal Laboratories for Materials Science and Technology

Überlandstrasse 129, 8600 Dübendorf (Switzerland)

$\left.{ }^{+}\right] \quad$ Equal contribution

Supporting information for this article is given via a link at the end of the document. industry for the efficient transformation of a carbon feedstock into valuable chemical intermediates. ${ }^{[7,15-17]}$ In particular, oxyhalogenation, comprising the reaction of a hydrocarbon with $\mathrm{O}_{2}$ and a hydrogen halide $(\mathrm{HX}, \mathrm{X}=\mathrm{Cl}, \mathrm{Br})$, has been demonstrated as a promising strategy for the selective functionalization of natural gas to yield methyl halides $\left(\mathrm{CH}_{3} \mathrm{X}\right)$ or olefins. Various materials based on europium oxyhalides (EuOX), cerium oxide $\left(\mathrm{CeO}_{2}\right)$, and titanium oxide $\left(\mathrm{TiO}_{2}\right)$ have been identified to efficiently catalyze these reactions. ${ }^{[18-23]}$ Particularly, in case of methane oxyhalogenation, the superior performance of these materials was related to their balanced redox properties, enabling the oxidation of $\mathrm{HX}$, an important step for activity, while suppressing the oxidation of the desired methyl halides. ${ }^{[22]}$ Still, the high reaction exothermicity imposes the practical challenge of designing catalysts capable of minimizing the formation of hot spots, which can detriment both the selectivity and stability. This issue could be addressed by embedding the active phase in a thermally conductive and chemically inert matrix such as silicon carbide. Recently, the controlled oxidation of a titanium carbide-silicon carbide ( $\mathrm{TiC}-\mathrm{SiC}$ ) ceramic composite to $\mathrm{TiO}_{2}-\mathrm{SiC}$ was shown to yield a high-performance photocatalyst for the degradation of 2-propanol, ${ }^{[23]}$ as well as an efficient carrier for cobalt nanoparticles in Fischer-Tropsch synthesis, which was attributed to the combination of the thermal conductivity of SiC and the favorable cobalt- $\mathrm{TiO}_{2}$ interactions. ${ }^{[25]}$ The controlled transformation of $\mathrm{TiC}$ into $\mathrm{TiO}_{2}$ in oxidative reaction environments could open further opportunities to develop efficient $\mathrm{TiO}_{2}$-based catalysts in alkane oxyhalogenation reactions.

In this work, we demonstrate the high performance of TiC-SiC in the oxychlorination and oxybromination of methane and ethane to desired methyl halides or ethylene, respectively. Detailed characterization of the fresh and activated samples by means of $X$-ray diffraction (XRD), thermogravimetric analysis (TGA), transmission electron microscopy, and Raman, X-ray photoelectron (XPS), and ${ }^{13} \mathrm{C}$ and ${ }^{29} \mathrm{Si}$ nuclear magnetic resonance spectroscopies enabled elucidation of the kinetics and mechanism of the selective activation of TiC-SiC under reaction conditions. The beneficial impact of the intimate interaction between Ti-based phases and the $\mathrm{SiC}$ matrix is proven by comparison with physical mixtures and bulk $\mathrm{TiO}_{2}$.

\section{Results and Discussion}

\section{Characterization of TiC-SiC}

The bulk composition and porosity of TiC-SiC were assessed by $\mathrm{X}$-ray fluorescence (XRF) and $\mathrm{N}_{2}$ sorption analyses (Table 1). The results revealed a total titanium content of $16.0 \mathrm{wt} . \%$ and the typical surface area $\left(83 \mathrm{~m}^{2} \mathrm{~g}^{-1}\right)$ and interparticle porosity (Supporting Information Figure S1) of this type of material. The 
Table 1. Composition and porosity of the TiC-SiC composite in fresh form and after activation in methane oxychlorination (MOC) and oxybromination (MOB), and in ethane oxychlorination (EOC), and oxybromination (EOB).

\begin{tabular}{lccc}
\hline Sample & Ti content $/$ wt. $\%$ & $S_{\mathrm{BET}} / \mathrm{m}^{2} \mathrm{~g}^{-1}$ & $V_{\text {pore }} / \mathrm{cm}^{3} \mathrm{~g}^{-1}$ \\
\hline Fresh & 16.0 & 83 & 0.12 \\
MOC & 17.5 & 24 & 0.09 \\
MOB & 17.9 & 26 & 0.09 \\
EOC & 18.4 & 25 & 0.08 \\
EOB & 16.5 & 65 & 0.09 \\
\hline
\end{tabular}

characteristic reflections of both $\mathrm{TiC}$ and $\mathrm{SiC}$ phases were observed by X-ray diffraction (Figure 1a). The inspection of the scanning transmission electron (STEM) micrographs coupled with energy-dispersive X-ray (EDX) mapping (Figure 2) verified the presence of the two phases, in which the TiC phase appeared embedded within the SiC matrix. The partial surface oxidation of both phases was evidenced, which was corroborated by the observance of the Raman band of the anatase phase of titania at $155 \mathrm{~cm}^{-1}$ (vide infra Figure 5a) with the diffraction peak of $\mathrm{SiO}_{2}$ (Figure 1a). Additional evidences

were provided by ${ }^{29} \mathrm{Si}$ magic angle spinning nuclear magnetic resonance (MAS NMR) and XPS spectroscopies, where the band corresponding to the presence of $\mathrm{Q}\left(\mathrm{SiO}_{4}\right)$ units at $-110 \mathrm{ppm}$ in the ${ }^{29} \mathrm{Si} M A S N M R$ spectrum (vide infra Figure 6a), ${ }^{[26]}$ and $\mathrm{SiO}_{2}$ and $\mathrm{TiO}_{2}$ components in the $\mathrm{Si} 2 p$ and Ti $2 p$ XPS core level spectra (vide infra Figure 5c, Supporting Information Figure S7), respectively, were observed. To determine the evolution of the $\mathrm{TiC}$ and $\mathrm{SiC}$ phases in an oxidative environment, TGA in air together with temperatureprogrammed oxidation with oxygen $\left(\mathrm{O}_{2}\right.$-TPO) were conducted (Figure 3). The weight increase from ca. $600 \mathrm{~K}$ to $800 \mathrm{~K}$ along with the formation of $\mathrm{CO}_{x}$ species was ascribed to the partial transformation of $\mathrm{TiC}$ into $\mathrm{TiO}_{2}$, which was completed at ca. $1000 \mathrm{~K}^{[27]}$ From ca. $800 \mathrm{~K}$ to $1000 \mathrm{~K}$, a weight loss accompanied by the evolution of the $\mathrm{m} / \mathrm{z} 28$ and 44 signals was evidenced. This could be the result of the simultaneous oxidation of the remaining $\mathrm{TiC}$ and of the residual carbon in the composite that was not carburized completely during the synthesis ${ }^{[28]}$ and/or of binders, such as methyl cellulose, polyvinyl alcohol, or polyethylene glycol among others that could have been added during the shaping process. ${ }^{[29]}$ At temperatures higher than $\mathrm{ca} .1000 \mathrm{~K}$, the transformation of $\mathrm{SiC}$ into $\mathrm{SiO}_{2}$ occurred consistent with the observed weight increase.

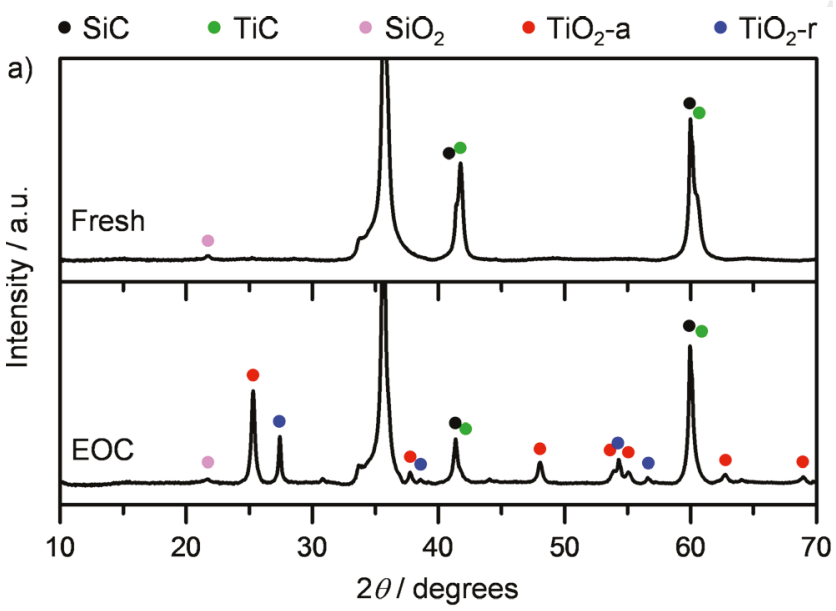

b)
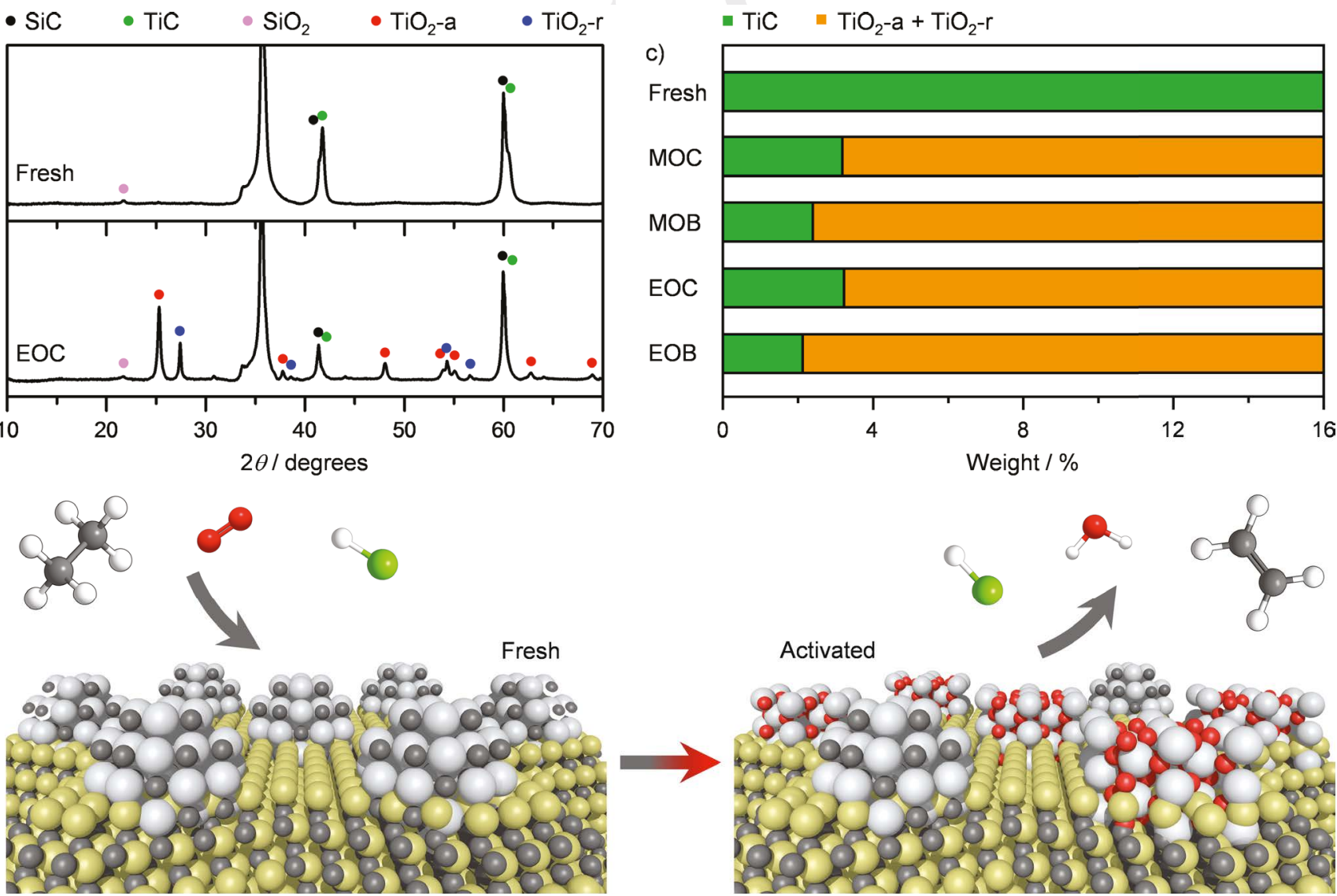

Figure 1. a) X-ray diffractograms of TiC-SiC in fresh form and after activation in EOC. The diffractograms of the samples after activation in MOC, MOB, and EOB are provided in Figure $\mathbf{S} 2$ of the Supporting Information. b) Schematic representation of the activation of TiC-SiC into TiO $-\mathrm{TiC}-\mathrm{SiC}$ in EOC. Color code: $\mathrm{S}$ (yellow), $\mathrm{C}$ (dark gray), $\mathrm{Ti}$ (light gray), $\mathrm{O}$ (red), $\mathrm{Cl}$ (green), $\mathrm{H}$ (white). c) Quantification of the $\mathrm{TiC}$ and $\mathrm{TiO}_{2}$ phases in the fresh and activated samples derived from TGA analysis. The TGA profiles are provided in Figure S3 of the Supporting Information. 


\section{Fresh}

a)
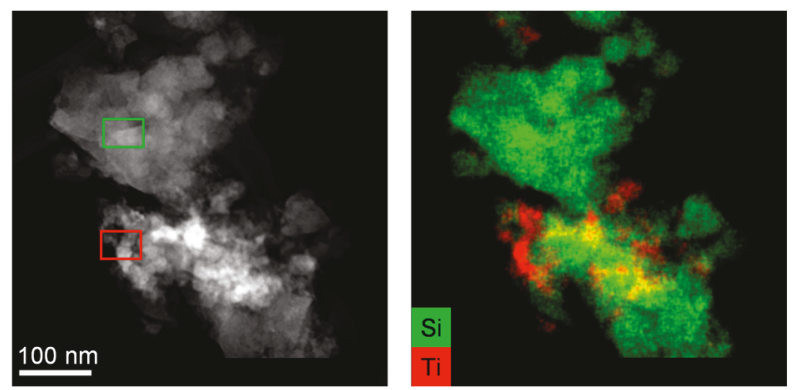

EOC
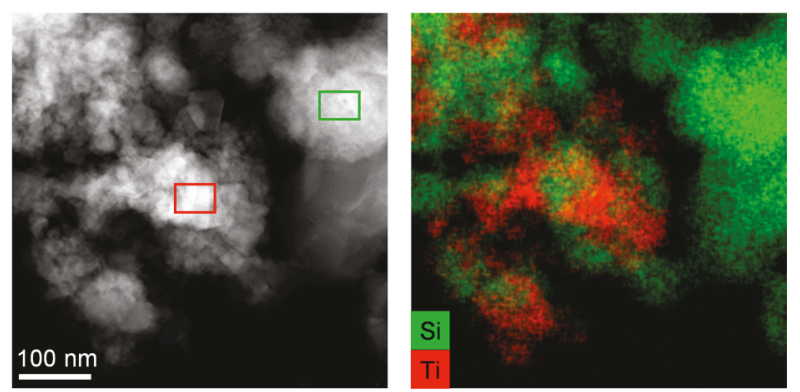

b)

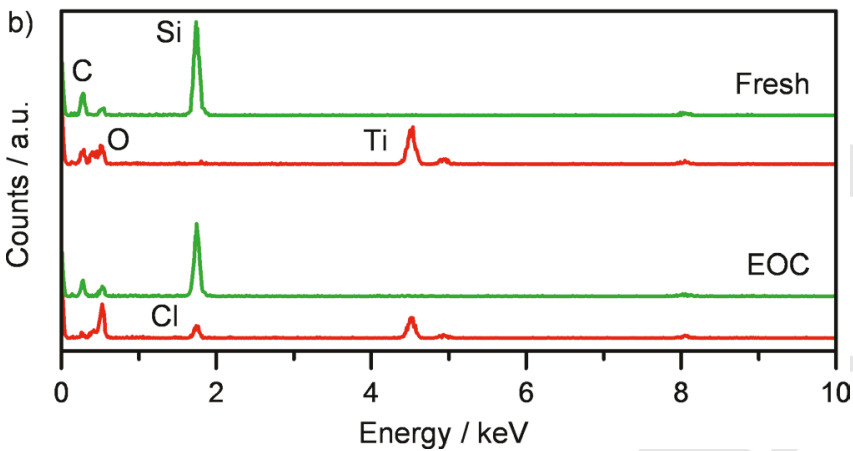

Figure 2. a) Scanning transmission electron micrographs (left) and corresponding elemental maps (right) of $\mathrm{TiC}-\mathrm{SiC}$ in fresh form and after activation in EOC. b) EDX spectra corresponding to the boxed Si (green box) and $\mathrm{Ti}$ (red box) rich regions. The scanning transmission electron micrographs with corresponding elemental maps and EDX spectra of TiC-SiC after activation in EOB are provided in Figure S4 of the Supporting Information.

\section{TiC-SiC as catalyst for alkane oxyhalogenation}

TiC-SiC was activated in methane and ethane oxyhalogenation under the same conditions previously reported by our group, ${ }^{[22,23]}$ i.e. variable temperature (from $680 \mathrm{~K}$ to $850 \mathrm{~K}$ ) and using a stoichiometric ratio of reactants (alkane: $\mathrm{HX}: \mathrm{O}_{2}=6: 6: 3$ ) in the inlet feed. The resulting material was active in all investigated reactions, as reflected by the rate of alkane $i$ consumed (Figure 4). This ranged between 0.5 and $1.5 \mathrm{~mol}_{\mathrm{CH}_{4}} \mathrm{~h}^{-1} \mathrm{~mol}_{\mathrm{Ti}}^{-1}$ at $723 \mathrm{~K}$ and $850 \mathrm{~K}$, respectively in methane oxychlorination (MOC), whereas a higher level of activity was attained when the activation was conducted under methane oxybromination (MOB) conditions $\left(2.7 \mathrm{~mol}_{\mathrm{CH}_{4}} \mathrm{~h}^{-1} \mathrm{~mol}_{\mathrm{Ti}}^{-1}\right.$ at $\left.850 \mathrm{~K}\right)$. Similarly, the activation in ethane oxybromination (EOB) lead to improved performance compared to that attained in ethane oxychlorination (EOC), particularly at low temperatures, where the composite achieved a rate of 2.8 and 0.9 mol $_{\mathrm{C}_{2} \mathrm{H}_{6}} \mathrm{~h}^{-1} \mathrm{~mol}_{\mathrm{Ti}}{ }^{-1}$, respectively, at $723 \mathrm{~K}$, but became similar upon increasing the reaction temperature.

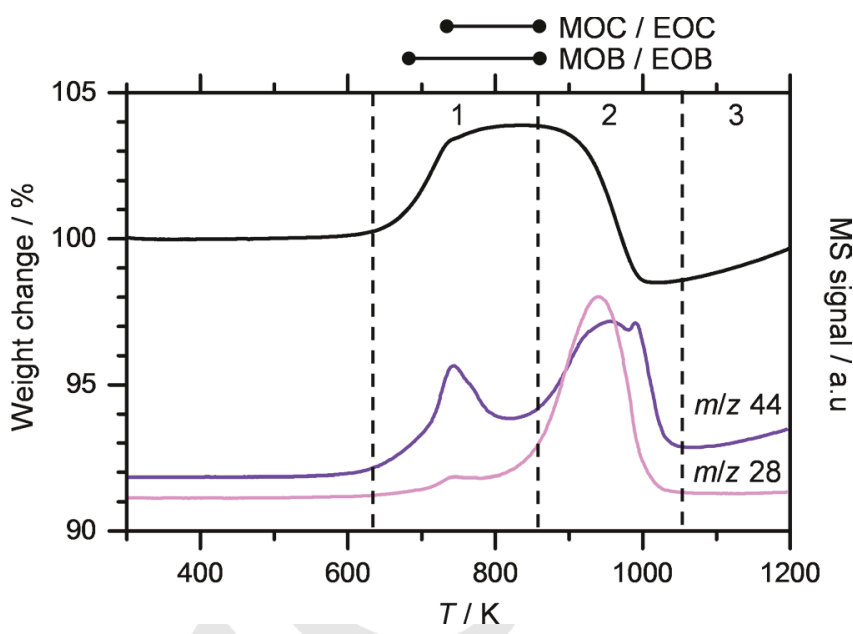

Figure 3. TGA analysis in air and $\mathrm{CO}_{x}$ evolution of TiC-SiC in fresh form. Regions 1, 2, and 3 represent the temperature windows where the following reactions take place: in Region 1, the oxidation of $\mathrm{TiC}$ to $\mathrm{TiO}_{2}$ and $\mathrm{CO}_{\mathrm{x}}$ occurs; in Region 2, the oxidation of the free carbon and binders that could be present in the sample to $\mathrm{CO}_{x}$ plus completion of the first reaction happen, and in Region 3, the oxidation of $\mathrm{SiC}$ to $\mathrm{SiO}_{2}$ and $\mathrm{CO}_{x}$ takes place. Operating temperatures in the studied reactions are shown on top of the figure.

Although activation under oxybromination conditions resulted in superior activity for both $\mathrm{C}_{1}$ and $\mathrm{C}_{2}$ alkanes, the trend of the selectivity to the desired product for the individual alkanes is similar regardless of the halogen source. The main difference between oxybromination and oxychlorination reactions lied on the variation of the selectivity to the desired $\mathrm{CH}_{3} \mathrm{X}$ or $\mathrm{C}_{2} \mathrm{H}_{4}$ with the temperature, which was more prominent in the former case. In particular, in MOC it decreased from $50 \%$ at $723 \mathrm{~K}$ to $40 \%$ at $850 \mathrm{~K}$ over the catalyst activated under these conditions (Figure 4a), ${ }^{[22]}$ whereas the composite activated in MOB showed $85 \%$ selectivity to $\mathrm{CH}_{3} \mathrm{Br}$ at the lowest temperature, which fell to $25 \%$ at $850 \mathrm{~K}$. In both cases, CO is the major byproduct with a selectivity lower than 55\% (Supporting Information Figure S5) over the MOC-activated catalyst and $\leq 60 \%$ at $850 \mathrm{~K}$ over the catalyst activated in MOB. On the other hand, for the samples activated in EOC and EOB, the selectivity to the desired $\mathrm{C}_{2} \mathrm{H}_{4}$ increased with the reaction temperature (Figure $\mathbf{4 b}$ ). For the EOC-activated catalyst, $\mathrm{C}_{2} \mathrm{H}_{4}$ generation increased from $70 \%$ to $80 \%$, whereas limited $\mathrm{CO}_{\mathrm{x}}$ production was observed $\left(\mathrm{S}_{\mathrm{CO}} \leq 12 \%\right.$ and $\left.\mathrm{S}_{\mathrm{CO}_{2}} \leq 2 \%\right)$. This behavior was accompanied by a decrease in the selectivity to $\mathrm{C}_{2} \mathrm{H}_{5} \mathrm{Cl} \quad\left(\mathrm{S}_{\mathrm{C}_{2} \mathrm{H}_{5} \mathrm{Cl}} \leq 20 \%\right.$; Supporting Information Figure S5), suggesting the occurrence of a consecutive oxychlorination-dehydrochlorination mechanism, in line with a recent study on olefin production via alkane oxychlorination. ${ }^{[23]}$ In the case of the EOB-activated catalyst, a pronounced increase in the selectivity to $\mathrm{C}_{2} \mathrm{H}_{4}$ from $15 \%$ to $65 \%$ was evidenced, along with a decrease in $\mathrm{CH}_{4}\left(\mathrm{~S}_{\mathrm{CH}_{4}} \leq 20 \%\right)$ and $\mathrm{CO}\left(S_{\mathrm{CO}} \leq 30 \%\right)$ generation.

\section{Characterization of activated TiC-SiC}

Table 1 summarizes the compositional and textural properties of activated TiC-SiC in methane and ethane oxyhalogenation. $\mathrm{N}_{2}$ sorption results evidenced the partial sintering upon activation, as shown by the decrease in the surface area. The titanium loading was preserved and any halogenation of the surface was very limited as confirmed by the EDX spectra (Figure 2 and 
Supporting Information Figure S4). XRD and TGA analyses of the activated samples (Figure 1 and Supporting Information Figures S2 and S3) revealed the partial evolution of TiC into $\mathrm{TiO}_{2}$ leading to $\mathrm{TiO}_{2}-\mathrm{TiC}-\mathrm{SiC}$, as schematized in Figure $\mathbf{1 b}$. This in situ formed $\mathrm{TiO}_{2}$ phase was responsible of the reducibility properties of the catalysts (Figure $\mathbf{5 b}$ ), which are essential in oxidation reactions. X-ray diffractograms evidenced the presence of different proportions of anatase and rutile phases depending on the reaction medium being anatase the main phase in all the activated samples (Supporting Information Figure S2). Although no changes were detected in the bulk by XRD analysis, XPS spectra revealed different Ti speciation on the catalyst surface depending on the activation conditions. In particular, $\mathrm{Ti}^{4+}$ species were present after activation under EOC and $E O B$ conditions, and a higher contribution from $\mathrm{Ti}^{3+}$ was evidenced on the EOB-activated catalyst. The latter might be ascribed to the stronger reducing ability of $\mathrm{HBr}$, as being observed in the oxidation of $\mathrm{HBr}$ to $\mathrm{Br}_{2}$ over $\mathrm{TiO}_{2}$ catalyst. ${ }^{[30]}$ The recrystallization of the $\mathrm{TiO}_{2}$ phase appeared to slightly increase
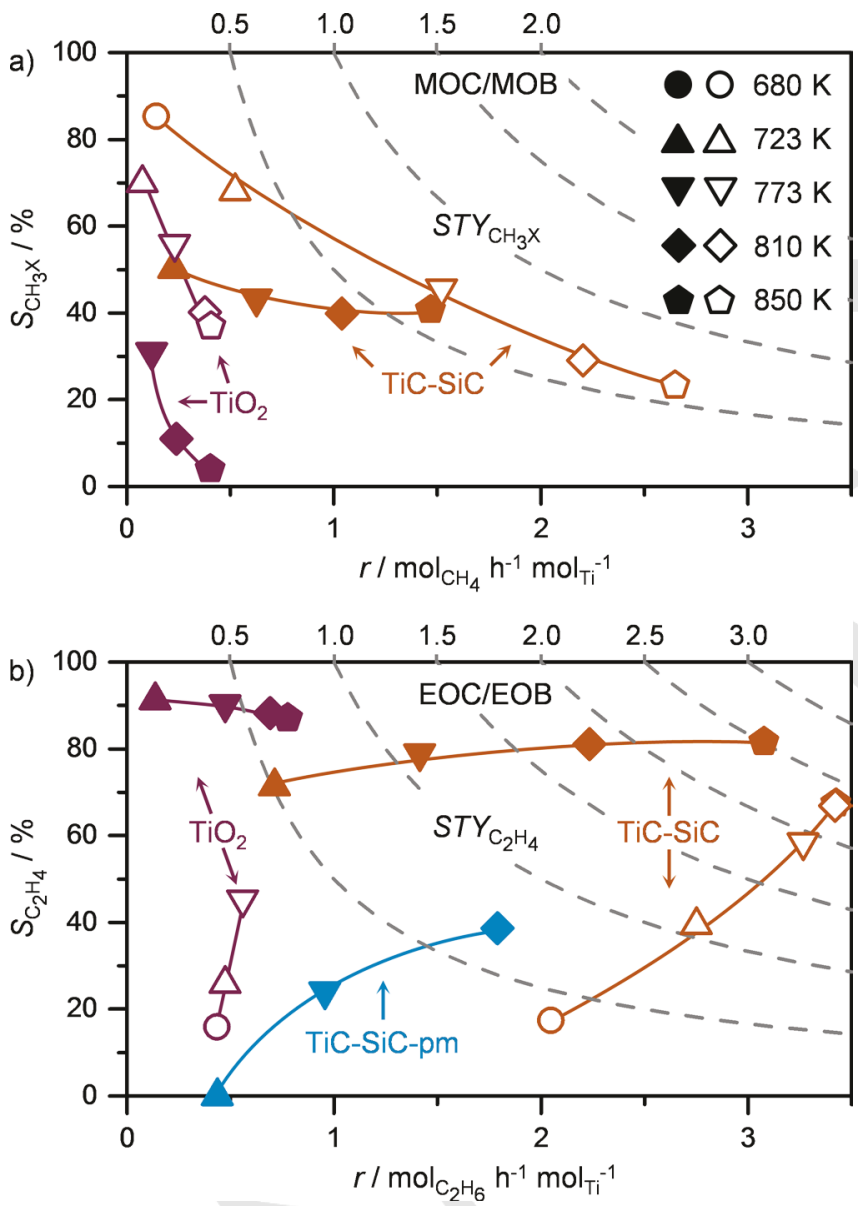

Figure 4. Selectivity to a) $\mathrm{CH}_{3} \mathrm{X}$ or b) $\mathrm{C}_{2} \mathrm{H}_{4}$ as a function of the rate of alkane consumption in the oxychlorination (solid symbols) and oxybromination (open symbols) of methane (MOC/MOB) and ethane (EOC/EOB) over TiC-SiC and $\mathrm{TiO}_{2}$. A comparison with a physical mixture of $\mathrm{TiO}_{2}$ and $\mathrm{SiC}\left(\mathrm{TiO}_{2}-\mathrm{SiC}-\mathrm{pm}\right)$ with the same $\mathrm{Ti}$ content (16 wt.\%) is provided for EOC. The dashed gray lines indicate the space-time-yield of product $j\left(j=\mathrm{CH}_{3} \mathrm{X}, \mathrm{C}_{2} \mathrm{H}_{4}\right)$ in $\mathrm{mol}_{j} \mathrm{~h}$ ${ }^{1} \mathrm{~mol}_{\mathrm{Ti}}{ }^{-1}$ and the different symbols refer to the reaction temperature. The selectivity to remaining reaction products is provided in Figures $\mathbf{5 5}$ and $\mathbf{S 6}$ of the Supporting Information. Feed composition: alkane: $\mathrm{HX}: \mathrm{O}_{2}: \mathrm{Ar}: \mathrm{He}=6: 6: 3: 4.5: 80.5$. the particle size compared to that of TiC. This was corroborated by the decrease in the interparticle porosity in the activated samples (Supporting Information Figure S1). In addition, the formation of $\mathrm{TiO}_{2}$ particles of well-defined morphology that remained embedded within the $\mathrm{SiC}$ matrix was evidenced as displayed in the micrographs of Figures 2 and Supporting Information Figure S4. The transformation of $\mathrm{TiC}$ into $\mathrm{TiO}_{2}$ was also observed by XPS analysis, showing only $\mathrm{TiO}_{2}$ on the surface of the activated catalysts (Figure $5 \mathrm{c}$ ), and an increase in
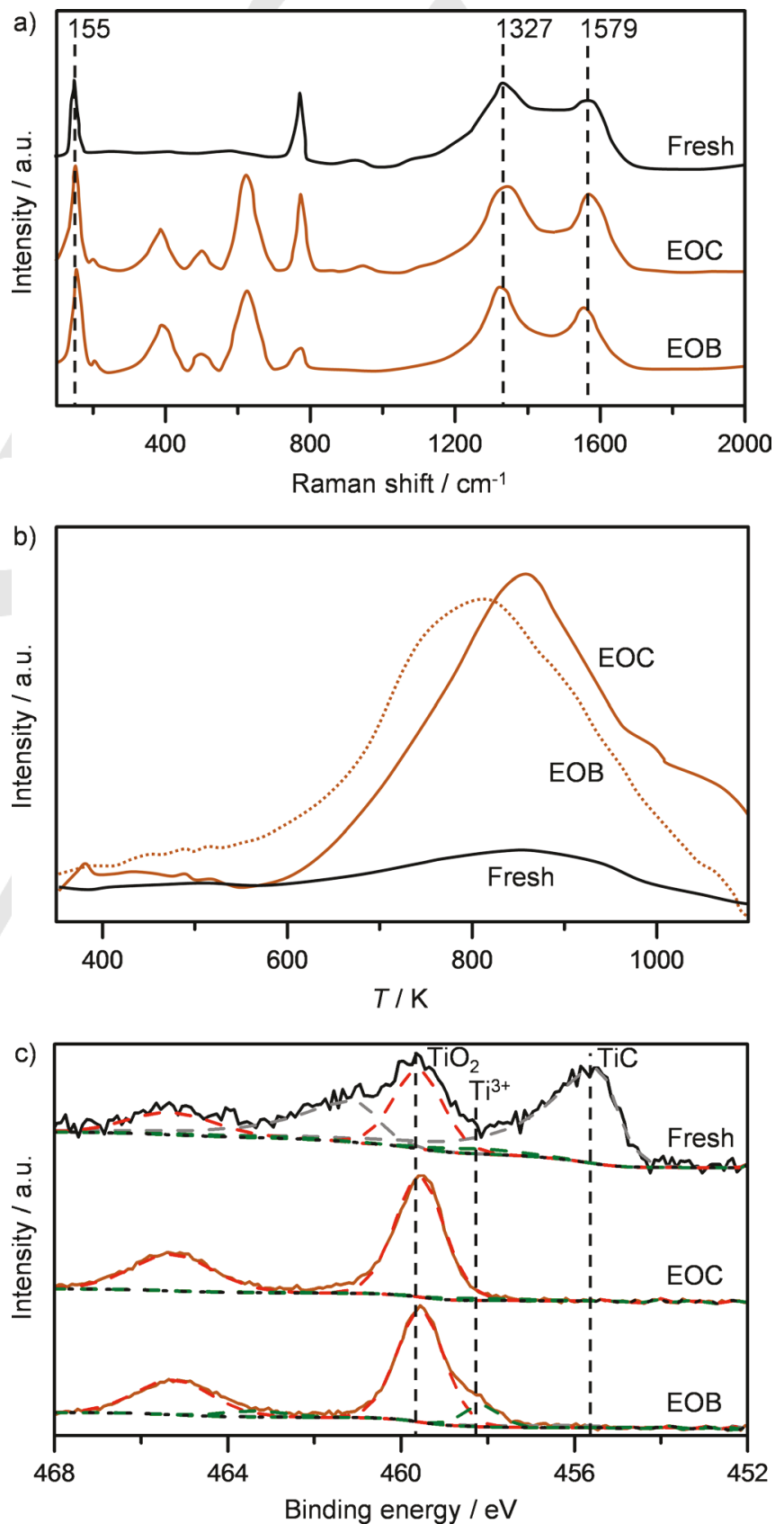

Figure 5. a) Raman spectra, b) temperature-programmed reduction with $\mathrm{H}_{2}$ $\left(\mathrm{H}_{2}\right.$-TPR) profiles, and c) $\mathrm{Ti} 2 p$ core level spectra of TiC-SiC in fresh form and after activation in EOC and EOB. The solid, dotted, and dashed lines represent the raw data, background, and fits of the different $\mathrm{Ti} 2 p$ contributions, respectively. Si $2 p, 01 s$, and $\mathrm{C} 1 s$ core level spectra are provided in Figure $\mathbf{S 7}$ of the Supporting Information. 
the elemental surface oxygen concentration after EOC (Supporting Information Table S1). On the other hand, analysis of the bulk material by TGA showed that a fraction of TiC remained unconverted after the reaction (Figure 1c) in accordance with the higher temperatures required for its complete transformation. ${ }^{[27]}$ The remaining loading was ca. $3 \mathrm{wt} . \%$, as derived from TGA analysis (Supporting Information Figure S3). The occurrence of TiC was also corroborated by Raman spectroscopy, where the characteristic bands of $\mathrm{TiC}$ at 1327 and $1579 \mathrm{~cm}^{-1}{ }^{\text {[31] }}$ were identified in the fresh sample and after activation in EOC and EOB (Figure 5a). Nevertheless, these bands can also be assigned to elemental carbon, coming either from the incomplete carburization of precursors in the fresh sample or from possible coke deposits on the activated catalysts. Accordingly, the TiC phase could not be detected by transmission electron microscopy, which suggests the presence of the unreacted $\mathrm{TiC}$ in the form of small nanoparticles well-dispersed in the $\mathrm{SiC}$ matrix.

The $\mathrm{Si}$ and $\mathrm{C}$ environments of the fresh and selected activated samples were assessed by ${ }^{29} \mathrm{Si}$ and ${ }^{13} \mathrm{C}$ MAS NMR spectroscopies, leading to similar results in all cases (Figure 6). The signal centered at $16 \mathrm{ppm}$ in the ${ }^{29} \mathrm{Si}$ MAS NMR spectra with two additional contributions at 20 and 25 ppm corresponds to the presence of partly amorphous SiC phase that kept unaltered during the reaction. ${ }^{[32,33]}$ The latter is corroborated by ${ }^{13} \mathrm{C}$ MAS NMR spectroscopy, which evidenced the occurrence of
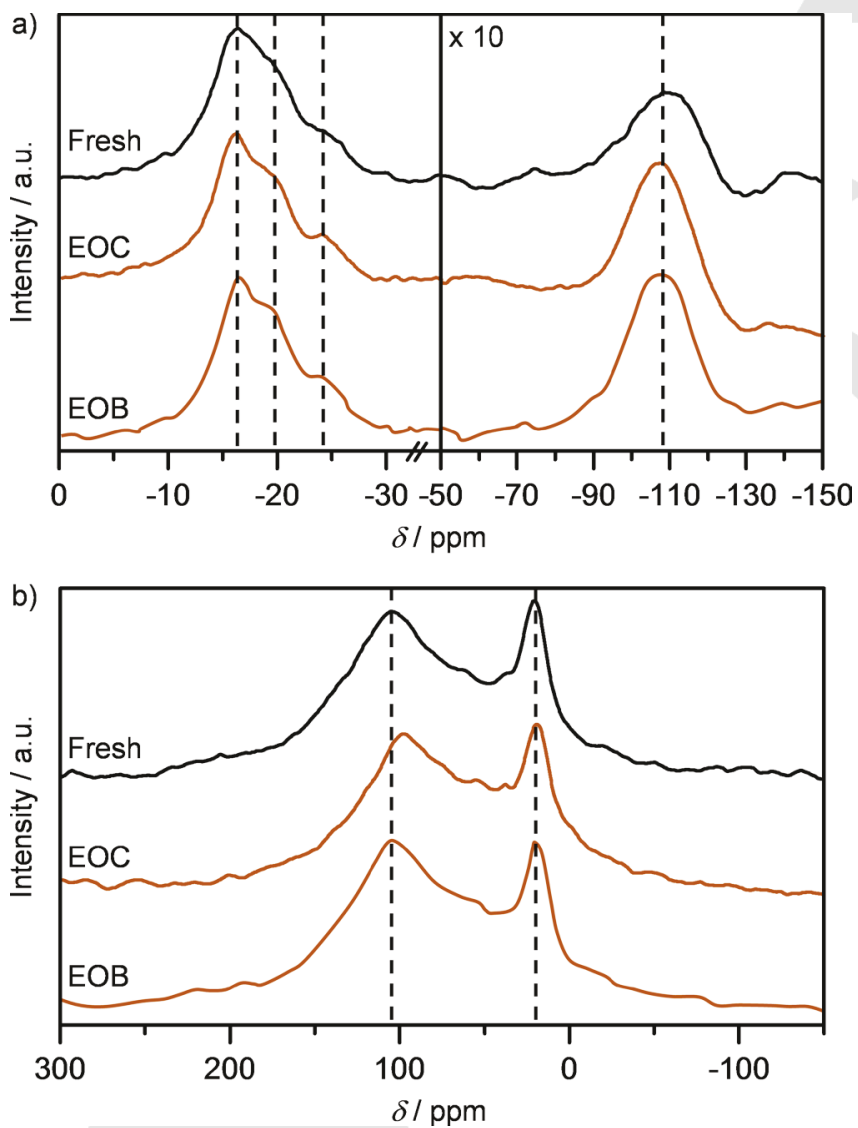

Figure 6 a) ${ }^{29} \mathrm{Si}$ and b) ${ }^{13} \mathrm{C}$ MAS NMR spectra of TiC-SiC in fresh form and after activation in $\mathrm{EOC}$ and $\mathrm{EOB}$. $s p$ and $s p^{2}$ carbon associated to $\mathrm{C} \equiv \mathrm{C}$ and $\mathrm{C}=\mathrm{C}$ bonds, respectively with a chemical shift centered at $103 \mathrm{ppm}$ in all the investigated samples. Together with the XRD analysis, which exhibited the characteristic diffraction peaks of the SiC phase (Supporting Information Figure S2), these results suggest the existence of crystalline domains dispersed in an amorphous matrix. The absence of additional bands at $-5,-35$, and $-70 \mathrm{ppm}$ (the latter not shown) in the ${ }^{29} \mathrm{Si}$ MAS NMR spectra discarded the formation of any bulk silicon oxycarbide phase, i.e. $\mathrm{SiC}_{3} \mathrm{O}, \mathrm{SiC}_{2} \mathrm{O}_{2}$, and $\mathrm{SiCO}_{3}$, respectively. ${ }^{[34,35]}$ On the other hand, the comparison of the signal at $-110 \mathrm{ppm}$ for the fresh and the activated samples revealed a small shift, which could be related to a possible oxygen redistribution during reaction. The intensity of this band evidenced a negligible increase upon activation, thus suggesting the stability of the SiC phase towards oxidation under activation conditions in line with the XRD, TGA, and $\mathrm{O}_{2}$-TPO results (Supporting Information Figure S2 and Figure 3). Assessment of the ${ }^{13} \mathrm{C}$ MAS NMR spectra (Figure 6b) also corroborated these findings, as the intensity of the band ascribed to $\mathrm{SiC}(20 \mathrm{ppm})$ remained identical in all cases. On the other hand, XPS analysis has shown the presence of $\mathrm{SiO}_{2}$ that increased after activation in EOC and EOB (Supporting Information Figure S7), suggesting that SiC oxidation is limited to the surface of the catalyst.

After identifying the morphological and structural properties of $\mathrm{TiO}_{2}-\mathrm{TiC}-\mathrm{SiC}$ that led to the observed performance, the kinetics of the activation process of $\mathrm{TiC}-\mathrm{SiC}$ were elucidated in the oxidation of $\mathrm{HCl}(\mathrm{HCO})$ and $\mathrm{HBr}(\mathrm{HBO})$ to molecular chlorine and bromine, respectively. The selection of these reactions is based on two main reasons: (i) they have been suggested as important steps for the activity in methane oxyhalogenation, ${ }^{[22]}$ and (ii) the absence of the alkane enables the decoupling of the impact of the halogen from that of the alkane on the activation mechanism. Assessment of the activation in $\mathrm{HCO}$ and $\mathrm{HBO}$ upon increasing the reaction temperature (Figure 7a) led to a final material similar to that attained after activation in alkane oxyhalogenation as evidenced by the similar distribution of the anatase and rutile phases of $\mathrm{TiO}_{2}$ (Supporting Information Figures S2 and S8), suggesting that the alkane does not play an important role in the catalyst transformation. Subsequent evaluation with time-on-stream (tos) at a constant reaction temperature, i.e. $810 \mathrm{~K}$, under $\mathrm{HCO}$ and $\mathrm{HBO}$ conditions (Figure $\mathbf{7 b}$ ) revealed a progressive transformation into $\mathrm{TiO}_{2}$-TiC-SiC in both cases in parallel with the evolution of the activity. In particular, no activity was detected under $\mathrm{HCO}$ activation conditions within the first hour. After $2 \mathrm{~h}$ on stream, activation of the catalyst occurred as evidenced by the increase in the rate of chlorine production to $0.06 \mathrm{~mol}_{\mathrm{Cl}_{2}} \mathrm{~h}^{-1} \mathrm{~mol}_{\mathrm{Ti}}{ }^{-1}$, which remained constant for the successive $18 \mathrm{~h}$. On the other hand, bromine production raised from 2.3 to 3.2 mol $_{\mathrm{Br}_{2}} \mathrm{~h}^{-1} \mathrm{~mol}_{\mathrm{Ti}}^{-1}$ within the first $5 \mathrm{~h}$ on stream followed by a slight decrease in the activity that levelled off to 2.6 mol $_{\mathrm{Br}_{2}} \mathrm{~h}^{-1}$ mol $_{\mathrm{Ti}}{ }^{-1}$ after $10 \mathrm{~h}$ on stream. Although the activity stabilized faster under HCO than under $\mathrm{HBO}$ conditions, the catalyst was more active in alkane oxybromination, as previously discussed (Figure 4), which might be related to the easier activation of $\mathrm{HBr}$ over the catalyst, as reported for $\mathrm{TiO}_{2}$ in methane oxyhalogenation. ${ }^{[22]}$ The activated 
catalysts in $\mathrm{HCO}$ and $\mathrm{HBO}$ were characterized after $0.5,5$, and $20 \mathrm{~h}$ on stream. XRD analysis evidenced the formation of $\mathrm{TiO}_{2}$ after $0.5 \mathrm{~h}$ on stream in both cases, being rutile the major phase (Supporting Information Figure S9). This contrasted the attained results for the activated samples in the temperature-ramping alkane oxyhalogenation and $\mathrm{HX}$ oxidation experiments where anatase was the most prominent phase. The observed difference could be ascribed to the fact that the transformation from anatase to rutile proceeded progressively with the temperature increase, whereas the activation of $\mathrm{TiC}$ into $\mathrm{TiO}_{2}$ phases under $\mathrm{HCO}$ and $\mathrm{HBO}$ reaction conditions occurred at $810 \mathrm{~K}$, where rutile is the thermodynamically favored phase. ${ }^{[6]}$ Quantification of the evolution of $\mathrm{TiC}$ into $\mathrm{TiO}_{2}$ in the samples by TGA analysis demonstrated the continuous transformation with tos in both reactions (Figure 7c). XPS analysis of the samples subjected to $\mathrm{HBO}$ revealed an increase in the $\mathrm{SiO}_{2}$ component with increasing time, in agreement with the decrease of the SiC signal. In contrast, no significant changes are observed between the samples treated under $\mathrm{HCO}$ or HBO conditions (Supporting Information Figure S11). Contrarily to TGA analysis, no traces of the TiC phase are detected on the catalyst surface, thus suggesting the occurrence of TiC on the bulk of the catalyst. STEM coupled with elemental mapping of the activated samples after $0.5 \mathrm{~h}$ in $\mathrm{HBO}$ (Supporting Information Figure S12) confirmed the presence of $\mathrm{TiO}_{2}$ in line with the XRD and TGA results. However, the TiC phase could not be detected as previously observed for the activated samples in alkane oxyhalogenation. In addition, TGA results elucidated the kinetics of activation of $\mathrm{TiC}$ into $\mathrm{TiO}_{2}$, which was much faster under $\mathrm{HCO}$ than under $\mathrm{HBO}$ conditions. In the former reaction, no change in the TiC content (ca. $3 \mathrm{wt} . \%$ ) was observed after $5 \mathrm{~h}$ on stream, whereas for the activation in $\mathrm{HBO}$, the $\mathrm{TiC}$ loading in the composite decreased from 8 wt.\% to ca. 3 wt.\% between $5 \mathrm{~h}$ and $20 \mathrm{~h}$ on stream, respectively. These differences could be explained by the fact that bromine evolves much easier than chlorine from the $\mathrm{TiO}_{2}$ surface, ${ }^{[22,37]}$ resulting in much higher activity in $\mathrm{HBO}$ compared to $\mathrm{HCO}$, which leads to higher oxygen consumption, and therefore slower kinetics of activation.

\section{Comparison of TiC-SiC with benchmark catalysts in alkane oxyhalogenation}

The performance of $\mathrm{TiO}_{2}$-TiC-SiC was compared to that of bulk $\mathrm{TiO}_{2}$, a benchmark oxyhalogenation catalyst. ${ }^{[21-23]}$ In particular, we have used the anatase phase of $\mathrm{TiO}_{2}$, as it was the main phase observed upon activation of TiC-SiC. Although rutile is the benchmark morphology, we have confirmed the absence of phase sensitivity by contrasting the performance of the two morphologies in EOC (Supporting Information Figure S13). The comparison in terms of titanium-specific space time yields to the targeted $\mathrm{CH}_{3} \mathrm{X}$ or $\mathrm{C}_{2} \mathrm{H}_{4}$ evidenced up to three times higher values in all reactions (Figure 4), reaching 0.6 versus

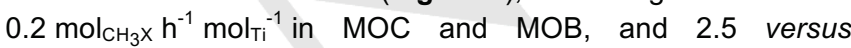
$0.7 \mathrm{~mol}_{\mathrm{C}_{2} \mathrm{H}_{4}} \mathrm{~h}^{-1} \mathrm{~mol}_{\mathrm{Ti}}^{-1}$ in EOC and EOB. In terms of product distribution, the composite exhibited enhanced selectivity to the desired $\mathrm{CH}_{3} \mathrm{X}$ or $\mathrm{C}_{2} \mathrm{H}_{4}$ compared to $\mathrm{TiO}_{2}$. Particularly, in the case of $\mathrm{MOC}$ TiC-SiC yielded $\mathrm{CH}_{3} \mathrm{Cl}\left(\mathrm{S}_{\mathrm{CH}_{3} \mathrm{Cl}}=40-50 \%\right)$, whereas $\mathrm{TiO}_{2}$ selectively produced $\mathrm{CO}\left(S_{\mathrm{CO}} \leq 90 \%\right)$ from the oxidation of $\mathrm{CH}_{3} \mathrm{Cl}$ as previously reported. ${ }^{[21]}$ In MOB, TiC-SiC showed also higher selectivity to $\mathrm{CH}_{3} \mathrm{Br}$ compared to $\mathrm{TiO}_{2}$ particularly at low temperatures. In EOC, the selectivity to $\mathrm{C}_{2} \mathrm{H}_{4}$ increased over $\mathrm{TiC}-\mathrm{SiC}$ upon increasing the temperature whereas it slightly decreased for $\mathrm{TiO}_{2}$, ultimately converging to similar values, i.e. $84 \%$, at the highest temperature investigated. On the other hand, TiC-SiC showed higher selectivities to $\mathrm{C}_{2} \mathrm{H}_{4}$ than $\mathrm{TiO}_{2}$ in $\mathrm{EOB}$, i.e., $65 \%$ versus $45 \%$, respectively.
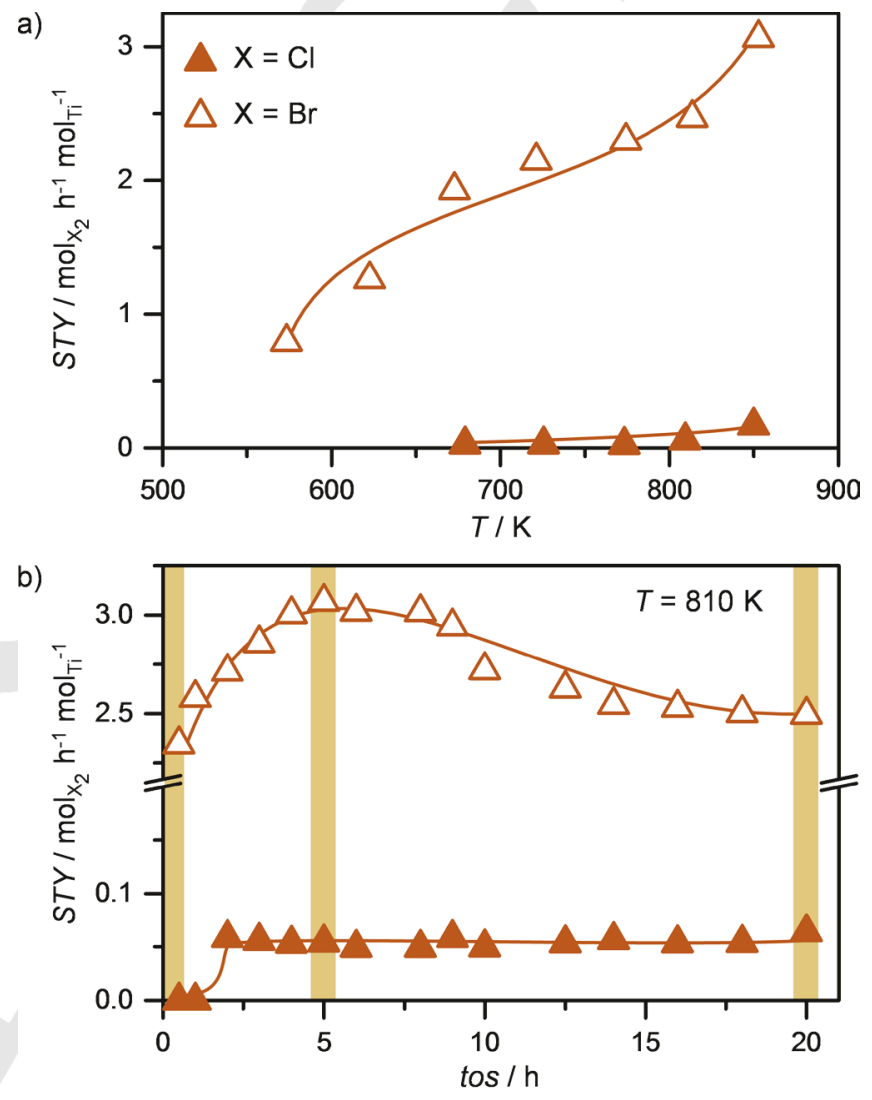

c)

$$
\text { - } \mathrm{TiC}=\mathrm{TiO}_{2}-\mathrm{a}+\mathrm{TiO}_{2}-\mathrm{r}
$$

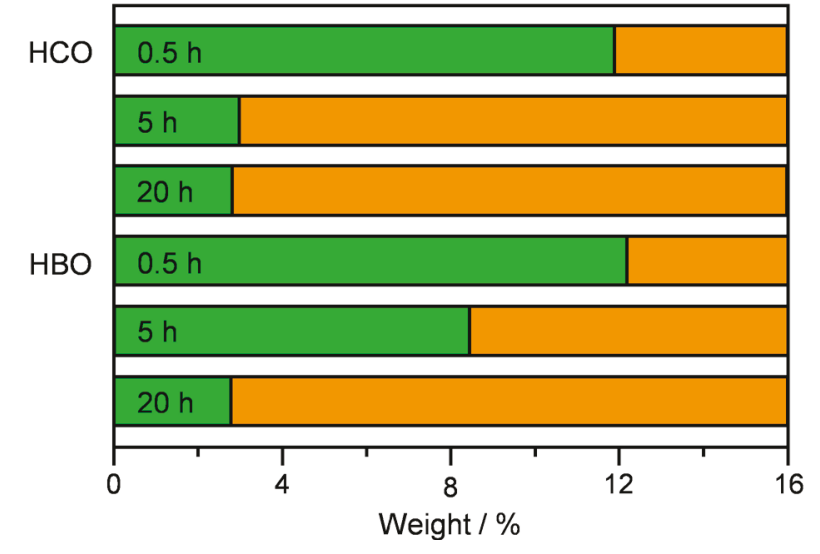

Figure 7. Space-time-yield of molecular halogen as a function of a) temperature or b) time-on-stream (tos) in $\mathrm{HCO}$ and $\mathrm{HBO}$ over TiC-SiC. The yellow boxes represent the different tos in $\mathrm{HCO}$ and $\mathrm{HBO}$ when the activated TiC-SiC were sampled for characterization. c) Quantification of the TiC and $\mathrm{TiO}_{2}$ phases derived from TGA analysis. The TGA profiles are provided in Figure $\mathbf{S} 10$ of the Supporting Information. 
To assess the impact of the in situ generated active phase in the $\mathrm{SiC}$ matrix on the observed performance, a physical mixture of $\mathrm{TiO}_{2}$ and $\mathrm{SiC}\left(\mathrm{TiO}_{2}-\mathrm{SiC}-\mathrm{pm}\right)$ with the same titanium loading as in the composite was evaluated in EOC (Figure 4b). The resulting mixture showed lower activity than TiC-SiC and significant differences in the product distribution (Supporting Information Figure S6). Indeed, despite the occurrence of similar oxychlorination-dehydrochlorination consecutive pathways in both cases, $\mathrm{TiO}_{2}$-SiC-pm displayed much lower selectivity to the desired $\mathrm{C}_{2} \mathrm{H}_{4}$ than the composite $\left(\mathrm{S}_{\mathrm{C}_{2} \mathrm{H}_{4}} \leq 40 \%\right.$ versus $\left.\leq 82 \%\right)$ and higher selectivity to the $\mathrm{C}_{2} \mathrm{H}_{5} \mathrm{Cl}$ intermediate $\left(\mathrm{S}_{\mathrm{C}_{2} \mathrm{H}_{5} \mathrm{Cl}} \leq 65 \%\right.$ versus $\leq 20 \%$ ). These results suggest the beneficial effect of the embedment of the in situ generated $\mathrm{TiO}_{2}$ in the thermally conductive $\mathrm{SiC}$ matrix. By comparing to the best benchmark catalysts, i.e. $\mathrm{CeO}_{2}$ for $\mathrm{MOC}^{[19,22]}$ and $\mathrm{EuOX}$ for both $\mathrm{MOB}^{[20]}$ and $\mathrm{EOC}^{[23]}$ the performance of TiC-SiC was inferior. Nevertheless, this material represents an interesting alternative owing to its high thermal conductivity, low price particularly in relation to EuOX, and its availability as a commercial technical catalyst.

\section{Conclusions}

TiC-SiC composite was found to be active and selective in the oxyhalogenation of alkanes for natural gas upgrading, which represents the first application of this material as effective heterogeneous oxidation catalyst. The selectivity to methyl halides in methane oxychlorination (ca.50\%) and oxybromination (ca. 85\%) surpassed that of reference $\mathrm{TiO}_{2}$ anatase (ca. 30 and $70 \%$, respectively). Similarly, in ethane oxybromination the composite reached ca. $70 \%$ selectivity to ethylene versus $45 \%$ obtained over $\mathrm{TiO}_{2}$ anatase, whereas analogous selectivities to ethylene (ca. $85 \%$ ) were attained in ethane oxychlorination. With respect to titanium, up to three times higher space time yields to the targeted product were observed in all reactions. Based on extensive characterization, this behavior was attributed to the in situ formation of the active phase via the selective partial oxidation of $\mathrm{TiC}$ into $\mathrm{TiO}_{2}$. The latter remained embedded within the thermally conductive $\mathrm{SiC}$ matrix, facilitating heat dissipation, which seems beneficial for the superior selectivity as evidenced by the comparison with the reference physical mixture of $\mathrm{TiO}_{2}$ anatase and $\mathrm{SiC}$ in ethane oxychlorination (ca. $85 \%$ versus $40 \%$ selectivity to ethylene). Assessment of the kinetics of the activation process of the composite in $\mathrm{HCl}$ and $\mathrm{HBr}$ oxidation revealed a progressive transformation of a fraction of $\mathrm{TiC}$ into $\mathrm{TiO}_{2}$ concurrent with the stabilization of the activity. In addition to providing new insights on the structure and morphological characteristics of $\mathrm{TiC}-\mathrm{SiC}$ composites, the findings highlight the potential of this catalyst for selective natural gas upgrading, thus inspiring future studies over this material for novel catalytic applications.

\section{Experimental Section}

Materials. The commercial TiC-SiC composite used in this work was synthesized by SICAT GmbH \& Co. (TiC-SiC-E3-HP, 16.0 wt.\% Ti, extrudate form) using a modified Ledoux method, ${ }^{[29]}$ in which $\mathrm{TiO}_{2}-\mathrm{P} 25$ $\mathrm{Si}$, and $\mathrm{C}$ precursors are reacted at $1600 \mathrm{~K}$ under an argon atmosphere to allow the carburization and siliconation reactions to occur. The asreceived $\mathrm{TiC}-\mathrm{SiC}$ extrudates were crushed, sieved to the desired average particle size $\left(d_{\mathrm{p}}=0.4-0.6 \mathrm{~mm}\right)$, and used as such in the catalytic tests. Commercial $\mathrm{TiO}_{2}$ anatase (Sigma-Aldrich, anatase nanopowder, 99.5\%) and rutile (Sigma-Aldrich, rutile nanopowder, 99.5\%) were calcined at $873 \mathrm{~K}$ for $5 \mathrm{~h}\left(5 \mathrm{~K} \mathrm{~min}^{-1}\right)$ prior to use. The same $\mathrm{TiO}_{2}$ anatase was used to prepare a physical mixture with SiC (SICAT, SiC-E3-HP), denoted as $\mathrm{TiO}_{2}-\mathrm{SiC}-\mathrm{pm}$, with the same $\mathrm{Ti}$ content as in the TiC-SiC composite.

Characterization. X-ray diffraction (XRD) patterns were acquired in a PANalytical X'Pert PRO-MPD diffractometer using $\mathrm{Cu}-\mathrm{K} \alpha$ radiation $(\lambda=0.154 \mathrm{~nm})$. The data was recorded in the $10-70^{\circ} 2 \theta$ range with an angular step size of $0.017^{\circ}$ and a counting time of $4.1 \mathrm{~s}$ per step $\mathrm{N}_{2}$ sorption at $77 \mathrm{~K}$ was measured in a Micromeritics TriStar II analyzer. Prior to the measurements, the samples were evacuated at $573 \mathrm{~K}$ for $3 \mathrm{~h}$ X-ray fluorescence spectroscopy (XRF) was used to quantify the $\mathrm{Ti}$ content by using an Orbis Micro instrument equipped with a Rh source operated at $35 \mathrm{kV}$ and $500 \mu \mathrm{A}$. Thermogravimetric analysis (TGA) was performed using a Mettler-Toledo TGA/DSC 1 Star system. The solid was pretreated in flowing air $\left(45 \mathrm{~cm}^{3} \mathrm{~min}^{-1}\right)$ at $393 \mathrm{~K}$ for $2 \mathrm{~h}$ followed by heating $\left(5 \mathrm{~K} \mathrm{~min}^{-1}\right)$ in the same atmosphere to $1223 \mathrm{~K}$. Temperatureprogrammed reduction with hydrogen $\left(\mathrm{H}_{2}\right.$-TPR) and oxidation with $\mathrm{O}_{2}$ $\left(\mathrm{O}_{2}\right.$-TPO) were performed in a Micromeritics Autochem II 2920 analyzer coupled with a OmniStar quadrupole mass spectrometer (MS). In both analyses, the solid was loaded into a U-shaped quartz micro-reactor, pretreated in $\mathrm{He}\left(20 \mathrm{~cm}^{3} \mathrm{~min}^{-1}\right)$ at $473 \mathrm{~K}$ for $1 \mathrm{~h}$, and cooled to $323 \mathrm{~K}$. The $\mathrm{H}_{2}$-TPR analysis was carried out in 5 vol. $\%$ of $\mathrm{H}_{2}$ in $\mathrm{N}_{2}\left(20 \mathrm{~cm}^{3} \mathrm{~min}^{-1}\right)$, ramping the temperature from $323 \mathrm{~K}$ to $1273 \mathrm{~K}$ at a heating rate of $10 \mathrm{~K} \mathrm{~min}^{-1}$. For $\mathrm{O}_{2}-\mathrm{TPO}$ analysis, the samples were heated in a mixture comprising 20 vol. $\% \mathrm{O}_{2}$ in $\mathrm{He}\left(20 \mathrm{~cm}^{3} \mathrm{~min}^{-1}\right)$ to $1273 \mathrm{~K}$ at $10 \mathrm{~K} \mathrm{~min}^{-1}$. Scanning transmission electron (STEM) micrographs were acquired on a Talos F200X instrument operating at $200 \mathrm{kV}$ and equipped with a highangle annular dark-field (HAADF) detector as well as an energydispersive X-ray spectrometer (EDX). X-ray photoelectron spectroscopy (XPS) was conducted using a Physical Electronics (PHI) Quantum 2000 X-ray photoelectron spectrometer featuring monochromatic Al K $\alpha$ radiation, generated from an electron beam operated at $15 \mathrm{kV}$ and $32.3 \mathrm{~W}$. The energy scale of the instrument was calibrated using Au and $\mathrm{Cu}$ reference samples. The samples were firmly pressed onto indium foil patches, which were then mounted onto a sample plate and introduced into the spectrometer. The analysis was conducted at $1 \times 10^{-6} \mathrm{~Pa}$, with an electron take off angle of $45^{\circ}$ and a pass energy of $23.50 \mathrm{eV}$. Charge compensation during the measurement was achieved using a low energy electron source. The spectra were then shifted by aligning the main component of the C $1 \mathrm{~s}$ core level spectra to $284.8 \mathrm{eV}$. Surface elemental concentrations were determined in atomic percent using the measured photoelectron peak areas after Shirley background subtraction and the built-in sensitivity factors for calculation. Fits of the Ti $2 p, \mathrm{C} 1 s$ and Si $2 p$ core level spectra were performed for a qualitative comparison of the samples. Binding energy ranges and boundary conditions for the fits were chosen according to the literature. ${ }^{[38]}$ Solid-state magic angle spinning nuclear magnetic resonance (MAS NMR) spectra of ${ }^{29} \mathrm{Si}$ and ${ }^{13} \mathrm{C}$ were recorded at a spinning speed of $10 \mathrm{kHz}$ on a Bruker Avance $400 \mathrm{MHz}$ spectrometer featuring a $4 \mathrm{~mm}$ probe head and $4 \mathrm{~mm} \mathrm{ZrO}_{2}$ rotors. ${ }^{29}$ Si MAS NMR spectra were collected using 1024 accumulations, $90^{\circ}$ pulses with a length of $4 \mu \mathrm{s}$, a recycle delay of $10 \mathrm{~s}$, and tetramethylsilane as reference. For ${ }^{13} \mathrm{C}$ MAS NMR spectra, 1024 accumulations, $90^{\circ}$ pulses with a length of $2.7 \mu \mathrm{s}$, a recycle delay of $10 \mathrm{~s}$, and glycine as reference were used. Raman spectroscopy was carried out in a confocal Raman microscope (WITec CRM 200) using a $532 \mathrm{~nm}$ diode laser. The microscope was operated in the backscattering mode with a 100x objective lens and $6 \mathrm{~mW}$ power. 
Catalytic tests. Activation of the TiC-SiC composite was performed under methane and ethane oxychlorination/oxybromination and $\mathrm{HCl}$ and $\mathrm{HBr}$ oxidation conditions at ambient pressure in a continuous-flow fixedbed reactor setup, which is detailed elsewhere. ${ }^{[22,23]}$ The gases $\mathrm{CH}_{4}$ (PanGas, purity 5.5), $\mathrm{C}_{2} \mathrm{H}_{6}$ (PanGas, purity 3.5), $\mathrm{HCl}$ (Air Liquide, purity 2.8, anhydrous), $\mathrm{HBr}$ (Air Liquide, purity 2.8, anhydrous), $\mathrm{O}_{2}$ (PanGas, purity 5.0), $\mathrm{Ar}$ (PanGas, purity 5.0; internal standard), and He (PanGas, purity 5.0 ; carrier gas), were fed by digital mass flow controllers (Bronkhorst $^{\circledR}$ ) to achieve a total volumetric flow, $F_{\mathrm{T}}$, of $6 \mathrm{LSTP} \mathrm{h}^{-1}$, containing a stoichiometric mixture (alkane: $\mathrm{HX}: \mathrm{O}_{2}: \mathrm{Ar}: \mathrm{He}=6: 6: 3: 4.5: 80.5$; $\mathrm{X}=\mathrm{Cl}, \mathrm{Br}$ ). In the case of $\mathrm{HCl}$ and $\mathrm{HBr}$ oxidation, the feed composition used was $\mathrm{HX}: \mathrm{O}_{2}: \mathrm{He}=6: 3: 91$. A quartz reactor (10 mm internal diameter) was loaded with the catalyst (catalyst weight, $W_{\text {cat }}=1 \mathrm{~g}$, particle size, $d_{\mathrm{p}}=0.4-0.6 \mathrm{~mm}$ ), and placed in an electrical oven. A K-type thermocouple fixed in a coaxial quartz thermowell with the tip positioned in the center of the catalyst bed was used to monitor the temperature during the reaction. Prior to testing, the catalyst bed was heated in a $\mathrm{He}$ flow to the desired temperature $(T=523-850 \mathrm{~K})$ and allowed to stabilize for at least $30 \mathrm{~min}$ before the reaction mixture was fed. The down-stream lining was heated at $393 \mathrm{~K}$ to prevent the condensation of reaction products. The effluent gas stream was sent through impinging bottles containing an aqueous $1 \mathrm{M} \mathrm{NaOH}$ solution for neutralization prior to release to the ventilation system. Quantification of $X_{2}$ was performed by its absorption in an impinging bottle filled with an aqueous $0.1 \mathrm{M} \mathrm{KI}$ solution $\left(\mathrm{X}_{2}+3 \mathrm{I}^{-} \rightarrow \mathrm{I}_{3}^{-}+2 \mathrm{X}^{-}\right)$followed by iodometric titration (Mettler Toledo G20 Compact Titrator) of the formed triiodide $\left(\mathrm{I}_{3}{ }^{-}+2 \mathrm{~S}_{2} \mathrm{O}_{3}{ }^{2-} \rightarrow 3 \mathrm{I}^{-}+\mathrm{S}_{4} \mathrm{O}_{6}{ }^{2-}\right)$ with an aqueous $0.01 \mathrm{M} \mathrm{Na}_{2} \mathrm{~S}_{2} \mathrm{O}_{3}$ solution (Aldrich, 99.99\%). Carbon-containing compounds $\left(\mathrm{CH}_{4}, \mathrm{C}_{2} \mathrm{H}_{6}, \mathrm{C}_{2} \mathrm{H}_{4}\right.$, $\mathrm{CH}_{3} \mathrm{X}, \mathrm{CH}_{2} \mathrm{X}_{2}, \mathrm{C}_{2} \mathrm{H}_{5} \mathrm{X}, \mathrm{CO}$, and $\mathrm{CO}_{2}$ ) and $\mathrm{Ar}$ were quantified using an online gas chromatograph equipped with a GS-Carbon PLOT column coupled to a mass spectrometer (GC-MS, Agilent GC 6890, Agilent MSD $5973 N)$.

The conversion of reactant $i, X_{i},\left(i: \mathrm{CH}_{4}\right.$, or $\left.\mathrm{C}_{2} \mathrm{H}_{6}\right)$ was calculated using Eq. 1,

$$
X_{i}=\frac{n_{i}^{\text {inlet }}-n_{i}^{\text {outlet }}}{n_{i}^{\text {inlet }}} \times 100, \%
$$

where $n_{i}^{\text {inlet }}$ and $n_{i}^{\text {outlet }}$ are the respective molar flows of the reactant $i$ at the reactor inlet and outlet.

The conversion of $\mathrm{HX}, X_{\mathrm{HX}}$, was calculated according to Eq. 2,

$X_{\mathrm{HX}}=\frac{2 \times n_{\mathrm{X}_{2}}{ }^{\text {outlet }}}{n_{\mathrm{HX}}{ }^{\text {inlet }}} \times 100, \%$

where $n_{\mathrm{X}_{2}}{ }^{\text {outlet }}$ and $n_{\mathrm{HX}}{ }^{\text {inlet }}$ denote the respective molar flows of $\mathrm{X}_{2}$ and $\mathrm{HX}$ at reactor outlet and inlet.

The reaction rate expressed with respect to the reactant $i, r,\left(i: \mathrm{CH}_{4}, \mathrm{C}_{2} \mathrm{H}_{6}\right.$, or $\mathrm{HX}$ ) and based on the titanium content was calculated using Eq. 3 ,

$r=\frac{n_{i}^{\text {inlet }}-n_{i}^{\text {outlet }}}{W_{\text {cat }} \times x_{\mathrm{Ti}}} \times M W_{\text {cat }}, \mathrm{mol}_{i} \mathrm{~h}^{-1} \mathrm{~mol}_{\mathrm{Ti}}^{-1}$

where $M W_{\text {cat }}$ and $x_{\mathrm{Ti}}$ are the catalyst molecular weight and molar titanium content, respectively.

The selectivity to product $j, S_{j}$, and the yield and space-time-yield of product $j, Y_{j}$, and $S T Y_{j}\left(j: \mathrm{CH}_{4}, \mathrm{C}_{2} \mathrm{H}_{4}, \mathrm{CH}_{3} \mathrm{X}, \mathrm{CH}_{2} \mathrm{X}_{2}, \mathrm{C}_{2} \mathrm{H}_{5} \mathrm{X}, \mathrm{CO}\right.$, and $\mathrm{CO}_{2}$ ) were calculated using Eqs. 4, 5, and 6, respectively,

$S_{j}=\frac{n_{j}^{\text {outlet }} \times N_{\mathrm{c}, j}}{\sum n_{j}^{\text {outlet }} \times N_{\mathrm{C}, j}} \times 100, \%$

Eq. 4

$Y_{j}=\frac{X_{i} \times S_{j}}{100}, \%$
$S T Y_{j}=\frac{n_{j}^{\text {outlet }}}{W_{\text {cat }} \times x_{\mathrm{Ti}}} \times M W_{\text {cat }}, \mathrm{mol}_{j} \mathrm{~h}^{-1} \mathrm{~mol}_{\mathrm{Ti}}^{-1}$

Eq. 6

where $n_{j}^{\text {outlet }}$ is the molar flow of the product $j$ at the reactor outlet and $N_{\mathrm{C}, j}$ is the number of carbon atoms in the compound $j$.

The error of the carbon mass balance, $\varepsilon_{\mathrm{C}}$, determined using Eq. 7,

$\varepsilon_{\mathrm{C}}=\frac{n_{i}^{\text {inlet }} \times N_{\mathrm{C}, i}-\left(n_{i}^{\text {outlet }} \times N_{\mathrm{C}, i}+\sum n_{j}^{\text {outlet }} \times N_{\mathrm{C}, j}\right)}{n_{i}^{\text {inlet }} \times N_{\mathrm{C}, i}} \times 100, \%$

was less than $5 \%$ in all experiments. All the catalysts were activated in the reaction mixture for a total time of $5 \mathrm{~h}$ and at a final temperature of $850 \mathrm{~K}$. Additionally, the activation of the $\mathrm{TiC}-\mathrm{SiC}$ composite in $\mathrm{HBr}$ and $\mathrm{HCl}$ oxidation at $810 \mathrm{~K}$ was monitored with time up to $20 \mathrm{~h}$. After the tests, the reactor was quenched to room temperature in $\mathrm{He}$ flow and the catalyst was retrieved for ex situ characterization.

\section{Acknowledgements}

This work was supported by ETH Research Grant ETH-04 16-1 and by the Swiss National Science Foundation (project no. 200021-156107). The authors thank Prof. Ralph Spolenak and ScopeM at ETH Zurich for using their facilities. Micha Calvo and Dr. Réne Verel are acknowledged for Raman and NMR analyses, respectively.

Keywords: alkane oxyhalogenation $\cdot$ natural gas upgrading • $\mathrm{C}-\mathrm{H}$ activation $\cdot$ titanium carbide-silicon carbide composite $•$ titanium oxide

[1] J. J. H. B. Sattler, J. Ruiz-Martinez, E. Santillian-Jimenez, B. M. Weckhuysen, Chem. Rev. 2014, 114, 10613-10653.

[2] H. Schwarz, Angew. Chem. 2011, 123, 10276-10297; Angew. Chem Int. Ed. 2011, 50, 10096-10115.

[3] E. V. Kondratenko, T. Peppel, D. Seeburg, V. A. Kondratenko, N. Kalevaru, A. Martin, S. Wohlrab, Catal. Sci. Technol. 2017, 7 366-381.

[4] E. McFarland, Science 2012, 338, 340-342.

[5] J. A. Labinger, J. E. Bercaw, Nature 2002, 417, 507-514.

[6] R. Khalilpour, I. A. Karimi, Energy 2012, 40, 317-328.

[7] R. Lin, A. P. Amrute, J. Pérez-Ramírez, Chem. Rev. 2017, 117, 4182-4247.

[8] J. Tollefson, Nature 2016, https://doi.org/10.1038/nature.2016.19141.

[9] U.S. Energy Information Administration, Monthly Energy Review, June 2016, U.S. Department of Energy, Washington, U.S., 2016.

[10] R. Horn, R. Schlögl, Catal. Lett. 2015, 145, 23-39.

[11] D. A. Goetsch, L. D. Schmidt, Science 1996, 271, 1560-1562.

[12] A. S. Bodke, D. A. Olschki, L. D. Schmidt, E. Ranzi, Science 1999, 285, 712-715.

[13] F. Cavani, N. Ballarini, A. Cericola, Catal. Today 2007, 127, 113-131.

[14] C. A. Gärtner, A. C. van Veen, J. A. Lercher, ChemCatChem 2013, 5, 3196-3217.

[15] J. Oliver-Meseguer, A. Doménech-Carbó, M. Boronat, A. Leyva-Pérez, A. Corma, Angew. Chem. 2017, 129, 6535-6539; Angew. Chem. Int. Ed. 2017, 56, 6435-6439.

[16] M. J. Dagani, H. J. Barda, T. J. Benya, D. C. Sanders, Ullmann's Encyclopedia of Industrial Chemistry, Vol. 6, Wiley-VCH, Weinheim, 2012, pp. 331-358.

[17] GTC Technology, 2017. Gas to Aromatics-GT-G2A ${ }^{\mathrm{SM}}$ http://www.gtctech.com, accessed November $23^{\text {rd }}, 2017,10: 00$ GMT. 
[18] A. Leyva-Pérez, D. Cómbita-Merchánt, J. R. Cabrero-Antonino, S. I. AlResayes, A. Corma, ACS Catal. 2013, 3, 250-258.

[19] J. He, T. Xu, Z. Wang, Q. Zhang, W. Deng, Y. Wang, Angew. Chem. 2012, 124, 2488-2492; Angew. Chem. Int. Ed. 2012, 51, 2438-2442.

[20] V. Paunović, R. Lin, M. Scharfe, A. P. Amrute, S. Mitchell, R. Hauert, J. Pérez-Ramírez, Angew. Chem. 2017, 129, 9923-9927; Angew. Chem. Int. Ed. 2017, 56, 9791-9795.

[21] V. Paunović, G. Zichittella, R. Verel, A. P. Amrute, J. Pérez-Ramírez, Angew. Chem. 2016, 128, 15848-15852; Angew. Chem. Int. Ed. 2016 55, 15619-15623.

[22] G. Zichittella, V. Paunović, A. P. Amrute, J. Pérez-Ramírez, ACS Catal. 2017, 7, 1805-1817.

[23] G. Zichittella, N. Aellen, V. Paunović, A. P. Amrute, J. Pérez-Ramírez, Angew. Chem. 2017,129, 13858-13862; Angew. Chem. Int. Ed. 2017, 56, 13670-13674.

[24] H. Yamashita, Y. Nishida, S. Yuan, K. Mori, M. Narisawa, Y. Matsumura, T. Ohmichi, I. Katayama, Catal. Today 2007, 120, 163-167.

[25] Y. Liu, B. de Tymowski, F. Vigneron, I. Florena, O. Ersen, C. Meny, P. Nguyen, C. Pham, F. Luck, C. Pham-Huu, ACS Catal. 2013, 3, 393-404.

[26] M. J. Henderson, A. Gibaud, J.-F. Bardeau, J. W. White, J. Mater. Chem. 2006, 16, 2478-2484.
[27] Y. Chen, H. Zhang, D. Ma, J. Ma, H. Ye, G. Qi, Y. Ye, Mater. Res. Bull. 2011, 46, 1800-1803.

[28] M. Zhou, P. Don D. Rodrigo, X. Wang, J. Hu, S. Dong, Y.-B. Cheng, J. Eur. Ceram. Soc. 2014, 34, 1949-1954.

[29] P. Nguyen, C. Pham, Appl. Catal., A 2011, 391, 443-454.

[30] M. Moser, I. Czekaj, N. López, J. Pérez-Ramírez, Angew. Chem. 2014 126, 8772-8777; Angew. Chem. Int. Ed. 2014, 53, 8628-8633.

[31] B. H. Lohse, A. Calka, D. Wexler, J. Alloys Compd. 2007, 434-435, 405-409.

[32] I.-K. Sung, C. M. Mitchell, D.-P. Kim, P. J. A. Kenis, Adv. Funct. Mat. 2005, 15, 1336-1342.

[33] M. M. Rahman, C. Y.-W. Yang, G. L. Harris in Amorphous and Crystalline Silicon Carbide II, Springer, Berlin, 1989, pp. 68.

[34] J. S. Hartman, M. F. Richardson, B. L. Sherriff, B. G. Winsborrow, J. Am. Chem. Soc. 1987, 109, 6059-6067.

[35] K. MacKenzie, M.E. Smith in Multinuclear Solid-State Nuclear Magnetic Resonance of Inorganic Materials, Pergamon, Oxford, 2002, pp. 256.

[36] X. Chen, S. S. Mao, Chem. Rev. 2007, 107, 2891-2959.

[37] M. Moser, V. Paunović, Z. Guo, L. Szentmiklósi, M.G. Hevia, M. Higham, N. López, D. Teschner, J. Pérez-Ramírez, Chem. Sci. 2016, 7, 2996-3005.

[38] V. Schier, H.-J. Michel, J. Halbritter, Fresenius J. Anal. Chem. 1993, 346, 227-232. 


\section{FULL PAPER}

TiC-SiC composite is shown for the first time as a high-performance catalyst for selective natural gas upgrading via oxyhalogenation chemistry. This is attributed to the in situ activation of $\mathrm{TiC}$ into $\mathrm{TiO}_{2}$ phase, which remains embedded into the thermally conductive SiC matrix, facilitating heat dissipation, thus improving selectivity control.

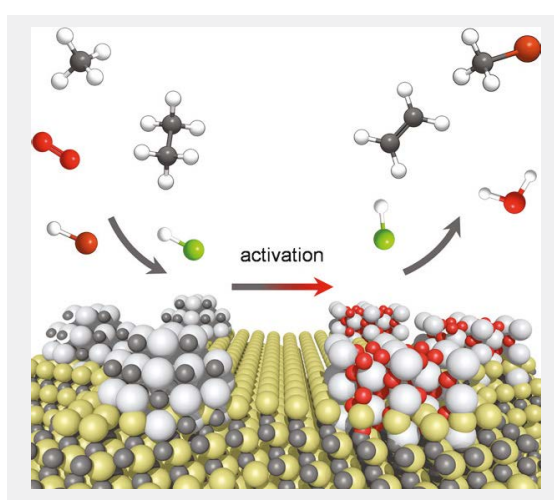

G. Zichittella, B. Puértolas, S. Siol,

V. Paunović, S. Mitchell,

J. Pérez-Ramírez*

Page No. - Page No.

Activated TiC-SiC Composite for Natural Gas Upgrading via Catalytic Oxyhalogenation 